\title{
Dendritic cells pulsed with Hsp70 and HBxAg induce specific antitumor immune responses in hepatitis $B$ virus-associated hepatocellular carcinoma
}

\author{
HUI WANG ${ }^{*}$, FANG FENG ${ }^{*}$, XIAO-PING WANG, ROU-SHU WANG, YING WU, \\ MIN-GAO ZHU, HONG ZHANG and ZHI-XIANG ZHUANG \\ Department of Oncology, The Second Affiliated Hospital, Soochow University, Suzhou, Jiangsu 215004, P.R. China
}

Received September 10, 2014; Accepted June 11, 2015

DOI: $10.3892 / \mathrm{mmr} .2015 .4654$

\begin{abstract}
Previous studies have drawn attention to dendritic cell (DC) vaccines; particularly the application of the tumor-associated antigen-targeted DC vaccine. The present study analyzed DCs derived from a normal individual and pulsed the cells with heat shock protein 70 peptide (Hsp70) and/or hepatitis B virus $\mathrm{x}$ antigen (HBxAg), a hepatocellular carcinoma (HCC)-associated antigen. It was then investigated whether this method of vaccination induced strong therapeutic antitumor immunity. The results revealed that the Hsp70/HBxAg complex-activated phenotype improves the functional maturation of DCs compared with using Hsp70 or HBxAg alone. Compared with either Hsp70 or HBxAg alone, matured DCs pulsed with the Hsp70/HBxAg complex stimulated a high level of autologous T-cell proliferation and induced HCC-specific cytotoxic T lymphocytes, which specifically killed HCC cells through a major histocompatibility complex class I mechanism. These results indicated that a vaccination therapy using DCs co-pulsed with the Hsp70/HBxAg complex is an effective strategy for immunotherapy and may offer a useful approach to protect against HCC.
\end{abstract}

\section{Introduction}

Hepatocellular carcinoma (HCC) causes high rates of mortality worldwide and is increasing in incidence (1). Epidemiological investigation demonstrates that the incidence of $\mathrm{HCC}$ is associated with the hepatitis B virus (HBV) x antigen ( $\mathrm{HBxAg}$ ) (2). The risk of developing HCC in HBxAg-positive individuals

Correspondence to: Professor Zhi-Xiang Zhuang, Department of Oncology, The Second Affiliated Hospital of Soochow University, 1055 San Xiang Road, Suzhou, Jiangsu 215004, P.R. China

E-mail: sdfeyzzx@sina.com

*Contributed equally

Key words: dendritic cells, heat shock protein 70, hepatitis B virus $\mathrm{x}$ antigen, cytotoxic $\mathrm{T}$ lymphocytes immunotherapy is higher compared with that in the HBxAg-negative populations $(1,3)$. Currently, the predominant clinical treatment for $\mathrm{HCC}$ is surgical resection and liver transplantation, however, the majority of patients lose surgical opportunity (4). Therefore, identifying a safe and efficient therapeutic strategy for HCC is of great global significance.

Immunotherapy, which stimulates tumor-specific immune responses has become one of the most promising emerging treatments (5). Previous studies have demonstrated the development of dendritic cell (DC) vaccination. DCs exhibit properties associated with innate and adaptive protective immune responses, induce tumor-specific effector T cells, and specifically decrease tumor mass and tumor relapse (6-8).

Heat shock proteins (HSPs), also termed stress proteins, are essential in the regulation of protein synthesis and vesicular trafficking, and have been demonstrated as potent adjuvants in cancer immunotherapy (9). Certain previous results suggest that the preparation of HSPs from various types of tumor can elicit different cytotoxic antitumor immune responses, and induce the development of distant metastases (10). HSPs can also bind and present tumor-associated antigens to antigen-presenting cells through major histocompatibility complex (MHC) class I and II molecules, leading to the activation of antitumor $\mathrm{CD} 8^{+}$ and $\mathrm{CD} 4^{+} \mathrm{T}$ cells (11).

However, whether using DCs co-pulsed with Hsp70/HBxAg complexes activates the cytotoxic antitumor immunoresponse in the HCC cells of HBxAg-positive individuals remains to be elucidated. The present study used DCs pulsed with Hsp70-peptide and/or HBxAg complexes to activate autologous $\mathrm{T}$ cells. The present study aimed to use pulsed DCs to develop a novel therapeutic strategy for the treatment of HCC, and also strived to provide a novel tumor vaccine approach against human HCC.

\section{Materials and methods}

Cell lines and regents. The human $\mathrm{LO} 2$ hepatic cell line, human SMMC-7721 HCC cell line and human K562 natural killer cell sensitive cell line were purchased from the American Type Culture Collection (Rockville, MD, USA). The human HepG2 $\mathrm{HCC}$ cell line $\left(\mathrm{HBxAg}^{+}\right)$, was provided by Professor Xiaodong Zhang (College of Life Sciences, Nankai University, Tianjin, 
China). The cells were cultured in RPMI-1640 medium, containing $10 \%$ fetal bovine serum (HyClone Laboratories Inc., Logan, UT, USA), $100 \mathrm{U} / \mathrm{ml}$ penicillin $\mathrm{G}$ and $100 \mu \mathrm{g} / \mathrm{ml}$ streptomycin (Gibco Life Technologies, Carlsbad, CA, USA), at $37^{\circ} \mathrm{C}$ in a humidified atmosphere of $95 \%$ air and $5 \% \mathrm{CO}_{2}$. The present study was approved ethics committee of the Second Affiliated Hospital of Soochow University (Suzhou, China).

HBxAg was purchased from MyBioSource, Inc. (San Diego, CA, USA). Hsp70 peptide was purified by Enzo Life Sciences, Inc. (Farmingdale, NY, USA).

Preparation of DCs. DCs were generated, as described previously (12). Briefly, peripheral blood mononuclear cells (PBMCs) were isolated from healthy donors (Suzhou Blood Center, Jiangsu, China), using Ficoll-Hypaque (TBD Science, Tianjin, China) density gradient centrifugation and cultured in RPMI-1640 medium, containing 10\% FBS for $2 \mathrm{~h}$. The non-adherent cells were removed for the isolation of $\mathrm{T}$ cells and the adherent cells were cultured for 7 days in RPMI-1640 medium, containing 10\% FCS, $100 \mathrm{ng} / \mathrm{ml}$ human granulocyte macrophage colony-stimulating factor (GM-CSF; Amoytop, Xiamen, China) and $10 \mathrm{ng} / \mathrm{ml}$ human interleukin (IL)-4 (Amoytop). The culture medium and cytokines were refreshed every 2 days. DCs were harvested on the 7th day.

Flow cytometric assay. The DCs were pulsed with Hsp70-peptide (ProSpec, Rehovot, Israel) and/or HBxAg (ProSpec) at $37^{\circ} \mathrm{C}$ for $4 \mathrm{~h}$, and were cultured for another $48 \mathrm{~h}$. The DCs were washed with cold phosphate-buffered saline (PBS), and incubated with murine monoclonal anti-human HLA-DR (cat. no. 560943), CD11c (cat. no. 560999), CD80 (cat. no. 560926), CD86 (cat. no. 560958) and CD83 (cat. no. 560929; BD Pharmingen, San Diego, CA, USA) for $1 \mathrm{~h}$ in ice. Following incubation, the cells were washed with cold PBS and were incubated with fluorescein isothiocyanate-conjugated with goat anti-mouse IgG (BD Pharmingen) for $30 \mathrm{~min}$ on ice. The cells were subsequently washed with cold PBS and fixed with 2\% paraformaldehyde (Sigma-Aldrich, St. Louis, MO, USA). The fluorescence intensity was analyzed using an Epics XL FACS Calibur (Beckman Coulter, Inc., Fullerton, CA, USA) and EXPO32 ADC CellQuest analysis software (Beckman Coulter, Inc.) (13).

IL-12 release enzyme-linked assay. Following treatment with different antigens, DCs were cultured in 6-well plates for $24 \mathrm{~h}$. Cytokine release in the supernatants was subsequently assessed by an ELISA using an IL-12 ELISA detection kit (R\&D Systems, Shanghai, China).

Mixed lymphocyte reaction. The mixed lymphocyte reaction was performed, as described previously (14). Briefly, $1 \times 10^{5} \mathrm{CD} 4^{+} \mathrm{T}$ cells were mixed with antigen-pulsed DCs and normal control DCs (R/S ratio, 10:1, 20:1 and 50:1). They were seeded into flat-bottomed 96-well plates in $200 \mathrm{ml}$ RPMI-1640 medium, containing $40 \mathrm{ng} / \mathrm{ml} \mathrm{IL}-2$, and were cultured at $37^{\circ} \mathrm{C}$ for 5 days. The cells were harvested onto glass fiber filters with a 96-well plate cell harvester (PLT 96WL; Corning Incorporated, Corning, NY, USA). Cell-associated radioactivity was determined using a cell counting kit- 8 assay kit
(Shanghai Qcbio Science \& Technologies Co., Ltd., Shanghai, China). The results of triplicate assays are expressed as the mean counts per minute \pm standard deviation.

Cytotoxicity assay. The autologous $\mathrm{CD} 8^{+} \mathrm{T}$ cells were incubated with stimulators (PBS-DCs, Hsp70-DCs, HBxAg and Hsp70/HBxAg-DCs) at a ratio of 20:1 in 96-well culture plates in RPMI-1640 medium, containing $40 \mathrm{ng} / \mathrm{ml} \mathrm{IL-2} \mathrm{for} 5$ days at $37^{\circ} \mathrm{C}$ with $5 \% \mathrm{CO}_{2}$. The cytotoxicity analysis was performed using a lactate dehydrogenase (LDH) release assay. Briefly, the effector $\mathrm{T}$ cells were harvested and incubated with $\mathrm{HepG} 2$ cells at ratios of 5:1, 10:1 and 20:1 in 96-microwell plates at $37^{\circ} \mathrm{C}$ and $5 \% \mathrm{CO}_{2}$ for $4 \mathrm{~h}$. The plates were subsequently centrifuged for $5 \mathrm{~min}$ at $250 \mathrm{xg}$, at room temperature. The supernatants from each well $(100 \mu \mathrm{l})$ were transferred into 96-well flat-bottomed microwell plates and $100 \mathrm{ml} \mathrm{LDH}$ substrate mixture was added. Following incubation for $15 \mathrm{~min}$, the absorbance was measured at $490 \mathrm{~nm}$ on an ELISA 550 Microplate reader (Bio-Rad Laboratories, Inc. Hercules, CA, USA). The CTL-mediated cytotoxicity was calculated using the following formula: Cytotoxicity-[1-(effector target-effector)/target] x 100.

Different cell types, HepG2 (HLA-A2 ${ }^{+} / \mathrm{HBxAg}^{+}$), SMMC-7721 (HLA-A2 $/ \mathrm{HBxAg}^{-}$), K562 (HLA-A2//HBx Ag-) and LO2-DCs human hepatic cells, were used as target cells. The cytotoxicity was subsequently detected by the LDH assay kit (Promega Corporation, Madison, WI, USA).

Reverse transcription-quantitative polymerase chain reaction $(R T-q P C R)$. The total RNA was extracted using TRIzol reagent (Invitrogen Life Technologies, Carlsbad, CA, USA). The total RNA $(2.5 \mu \mathrm{g})$ was reverse transcribed using a Superscript ${ }^{\mathrm{TM}}$ III kit (Invitrogen Life Technologies), according to the manufacturer's instructions. PCR amplification was performed in a $50 \mu \mathrm{l}$ PCR reaction mixture, containing $10 \mathrm{mM}$ Tris- $\mathrm{HCl}$ (pH 8.3), $50 \mathrm{mM} \mathrm{KCl}, 2 \mathrm{mM} \mathrm{MgCl}_{2}, 20$ pmol each primer set, 2 units Taq DNA polymerase (Beyotime Institute of Biotechnology, Jiangsu, China), $0.2 \mathrm{mM}$ dNTPs and $2 \mathrm{ml}$ cDNA. PCR was performed for 40 cycles at $95^{\circ} \mathrm{C}$ for $10 \mathrm{~min}, 95^{\circ} \mathrm{C}$ for $15 \mathrm{sec}$ and $60^{\circ} \mathrm{C}$ for $1 \mathrm{~min}$ in a $7900 \mathrm{HT}$ Fast Real-Time PCR System (ABI, Palo Alto, CA, USA), and analysis of the dissociation curve was performed at $95^{\circ} \mathrm{C}$ for $15 \mathrm{sec}$, $60^{\circ} \mathrm{C}$ for $1 \mathrm{~min}, 95^{\circ} \mathrm{C}$ for $15 \mathrm{sec}$ and $60^{\circ} \mathrm{C}$ for $15 \mathrm{sec}$. The nucleotide sequences of the oligonucleotide primers for $\mathrm{HBxAg}$ were as follows: Forward: 5'-ACCGACCTTGAGGCCTACTT-3' and reverse: 5'-GCTTGGCAGAGGTGAAAAAG-3' (Sangon Biotech Co., Ltd., Shanghai, China).

Immunoblot analysis. The total cellular proteins were extracted by lysing cells in a sodium dodecyl sulfate (SDS) sample buffer, containing $62.5 \mathrm{mM}$ Tris- $\mathrm{HCl}(\mathrm{pH} 6.8), 2 \%$ SDS, $1 \mathrm{mM}$ phenylmethylsulfonyl fluoride, $10 \mathrm{mg} / \mathrm{ml}$ pepstatin, $12.5 \mathrm{mg} / \mathrm{ml}$ leupeptin, $2 \mathrm{mg} / \mathrm{ml}$ aprotinin, $1 \mathrm{mM}$ sodium orthovanadate and $1 \mathrm{mM}$ sodium molybdate. The method of cell extraction for western blotting was performed, as described previously (15). The HBxAg used for immunoblot analysis was purchased from MyBioSource, Inc. (San Diego, CA, USA).

Adaptive immunotherapy in the xenograft model of nude mice. Female severe combined immunodeficiency (SCID) 
mice ( $\mathrm{n}=10$; age, 4 weeks; weight, $9.7 \pm 0.51 \mathrm{~g})$ were purchased from (Shanghai Laboratory Animal Center, Shanghai, China). The SCID mice were inoculated subcutaneously with $7.5 \times 10^{6}$ HepG2 tumor cells in $150 \mathrm{ml}$ Matrigel (Becton Dickinson, Bedford, MD, USA) and $50 \mathrm{ml}$ sterile PBS. Following tumor inoculation for 7 days, the SCID mice were randomized into three groups and treated with $\mathrm{T}$ cells $\left(2.5 \times 10^{6}\right)$ stimulated with the following: i) Fusion cells (cells expressing HBxAg and Hsp70); ii) DCs; or iii) PBS. The T cells were injected into tumors every 4 days and the tumors were measured each time using vernier calipers. Tumor volume was calculated as follows: $1 / 2 \mathrm{x}$ (length $\mathrm{x}$ width ${ }^{2}$ ).

Statistical analysis. The experiments and in vitro assays were performed at least three times. The differences between the mean values were assessed by Student's t-test. Statistical analysis was conducted using Prism 4 (GraphPad Software, Inc., La Jolla, CA, USA). $\mathrm{P}<0.05$ was considered to indicate a statistically significant difference.

\section{Results}

HepG2 cells stably express HBxAg. In order to determine the role of $\mathrm{HbxAg}$ in human hepatic cell lines, it was first confirmed that the HepG2 cell line stably expressed the HbxAg following transfection. Western blotting and RT-qPCR were used to detect the expression levels of HbxAg in the HepG2 cells. As shown in Fig. 1, the results revealed that the HepG2 cell line exhibited a high expression level of $\mathrm{HbxAg}$, following transfection.

Maturation of human DCs pulsed with different antigen complexes. To investigate the effects of antigen complexes derived from HepG2 cells on DCs, immature DCs were generated by culturing human PBMCs in the presence of human GM-CSF and IL-4 for 7 days. The immature DCs were incubated with antigen complexes at $37^{\circ} \mathrm{C}$ and were subsequently cultured for $48 \mathrm{~h}$. The expression levels of HLA-DR, CD86, CD11c, CD80 and CD83 were determined by flow cytometry. The expression levels of HLA-DR, CD86 co-stimulation molecule, CD83 maturation marker, CD11c and CD80 were significantly upregulated (Fig. 2A). These results indicated that antigen complexes induced the maturation of DCs, suggesting that antigen complexes effectively activated DCs.

Cytokine release of DCs pulsed with different antigens. The IL-12 release in the supernatants of DCs either pulsed or non-pulsed with different antigens was assessed by ELISA. The results revealed that the levels of IL-12 were significantly upregulated following infection for $24 \mathrm{~h}$. However, when the DCs were pulsed with Hsp70/HBxAg, the level of IL-12 was higher compared with that of DCs pulsed with PBS, HBxAg and Hsp70 (Fig. 2B). The results demonstrated that the antigens activated $\mathrm{CD} 4^{+}$and $\mathrm{CD} 8^{+} \mathrm{T}$ cells.

Induction of specific CTLs against HepG2 by DCs pulsed with Hsp70/HBxAg complexes. The functional capability of the CTLs responding to antigen-pulsed DCs was assessed by determining whether it specifically killed tumor cells. CD8 ${ }^{+}$ T cells were plated into 96-well plates in a medium containing
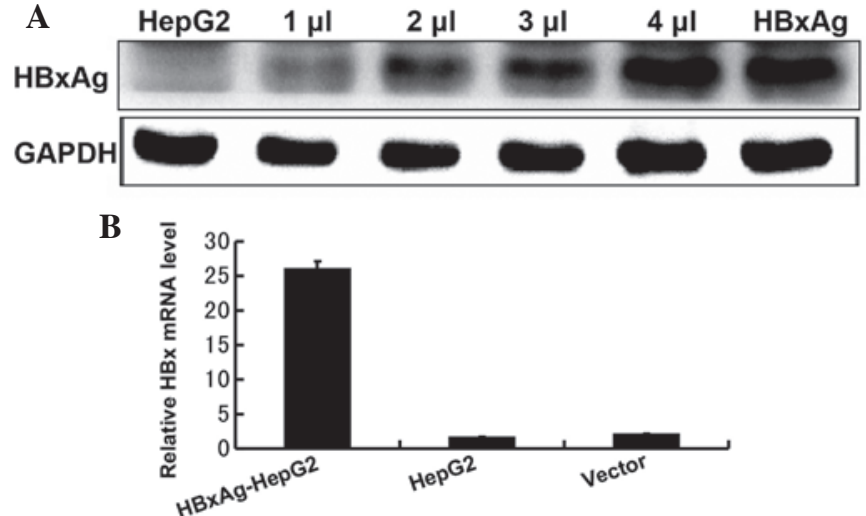

Figure 1. Protein and mRNA expression of $\mathrm{HBx}$ following transfection. (A) The protein expression of HBxAg in the HepG2 cells following transfection with HBxAg. (B) The relative mRNA expression of HBxAg in the HepG2 cells following transfection of $\mathrm{HBxAg}$. $\mathrm{HBxAg}$, hepatitis $\mathrm{B}$ virus $\mathrm{x}$ antigen.

A
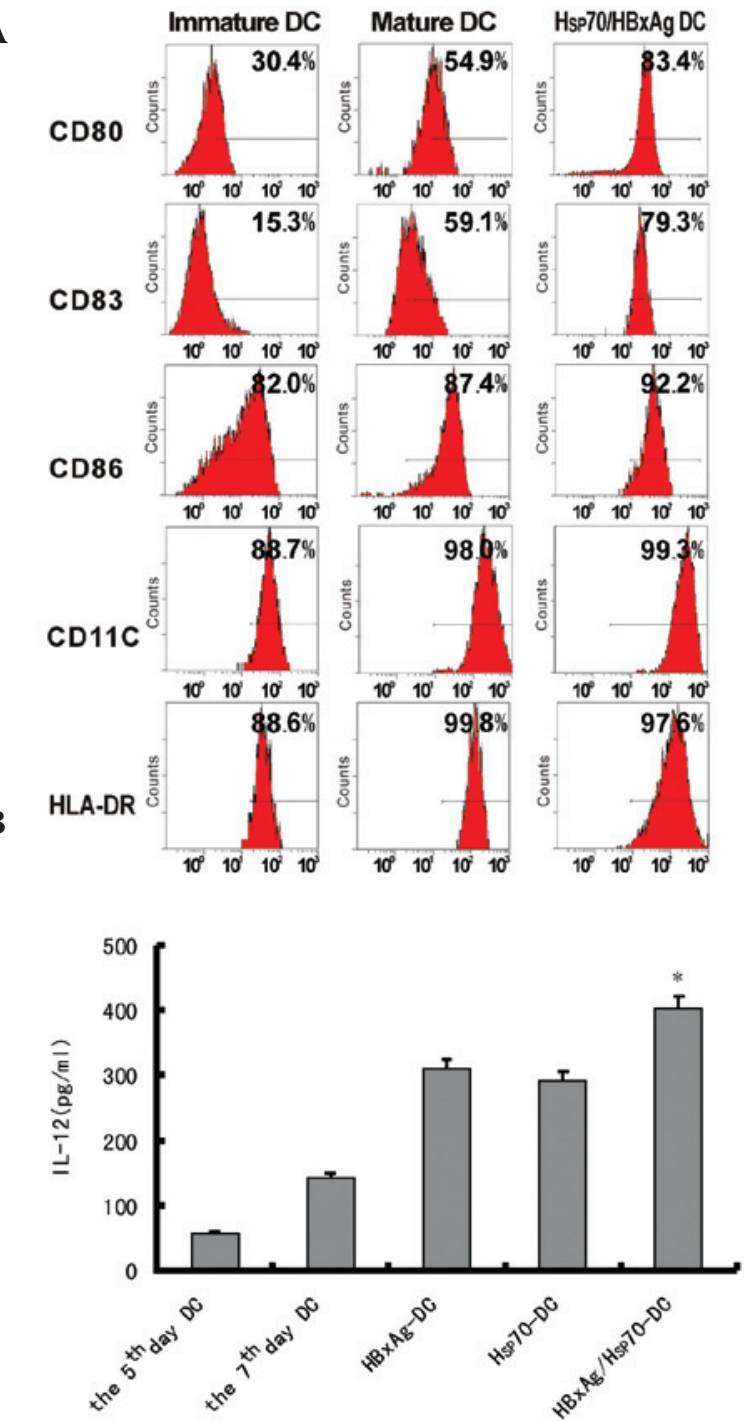

Figure 2. Detection of the cell surface markers of infected DCs by flow cytometry. (A) The cell surface markers of infected DCs were measured by flow cytometry. (B) IL-12 release in the supernatants of DCs was assessed by ELISA. The data are expressed as the mean \pm standard deviation. Statistical significance was calculated using the t-test $\left({ }^{*} \mathrm{P}<0.05\right.$, compared with the control). DC, dendritic cells; IL, interleukin; $\mathrm{HBxAg}$, hepatitis B virus $\mathrm{x}$ antigen; Hsp70, heat shock protein 70 . 


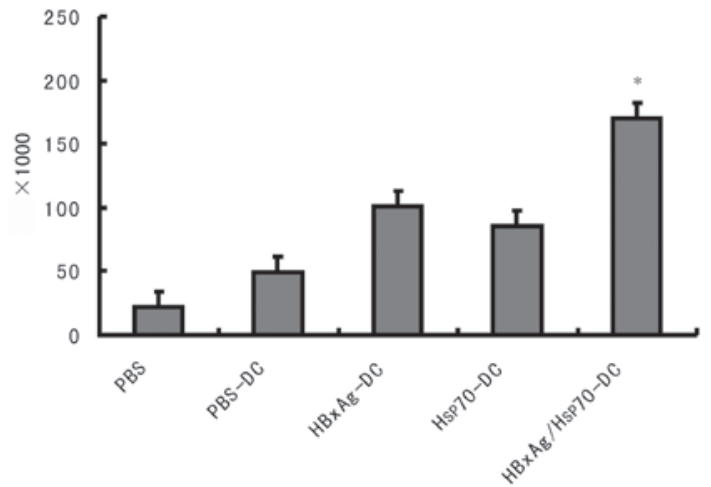

Figure 3. $\mathrm{CD}^{+} \mathrm{T}$ cell proliferation is activated by DCs pulsed with Hsp70 and/or HBxAg, as determined by the cell counting kit-8 assay. The T cells activated by DCs infected with $\mathrm{Hsp} 70 / \mathrm{HBx}$ Ag proliferated more effectively compared with those activated by DCs infected with HBxAg or those activated by DCs infected with Hsp70. The proliferation levels of PBS-DCs and PBS were significantly lower compared with the antigen-stimulated groups. The data are expressed as the mean \pm standard deviation. Statistical significance was calculated using the t-test ( $\mathrm{P}<0.05$, compared with the control). DC, dendritic cell; PBS, phosphate-buffered saline; Hsp70, heat shock protein $70 ; \mathrm{HBxAg}$, hepatitis B virus $\mathrm{x}$ antigen.

A

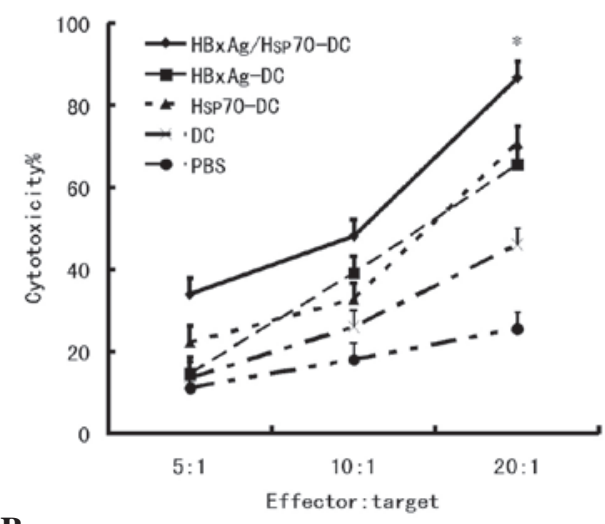

B

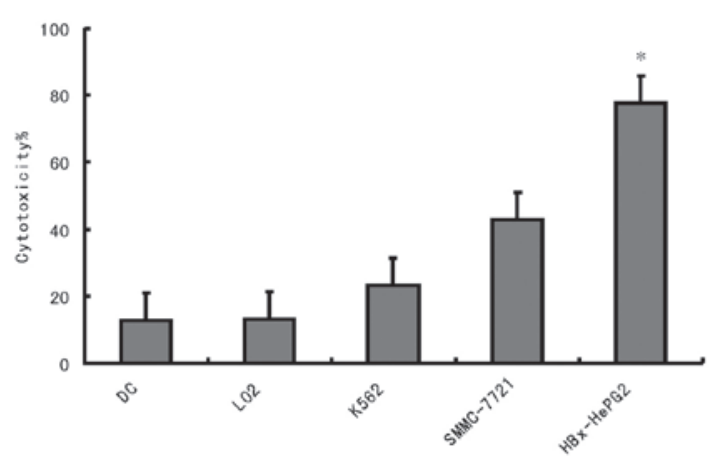

Figure 4. Cytotoxicity measured by LDH assay. DCs were incubated with Hsp70-peptide complexes and subsequent cocultured autologous T cells. The stimulated cells were harvested and the cytotoxicity was determined by the LDH assay. (A) The T cells were cocultured with autologous DCs pulsed with different complexes (HBxAg, Hsp70 or PBS) and were used as effector cells and HepG2 cells were used as target cells. (B) The T cells were cocultured with autologous DCs pulsed with Hsp70-peptide complexes and SMMC-7721, natural killer cell-sensitive cell line K562, LO2 and HepG2 cells. The results are expressed as the mean \pm standard deviation and each value represents the mean of three replicates. Statistical significance was calculated using a t-test ( $\mathrm{P}<0.05$, compared with control). LDH, lactose dehydrogenase; DC, dendritic cell; Hsp70, heat shock protein 70; HBxAg, hepatitis B virus $x$ antigen; $P B S$, phosphate-buffered saline.

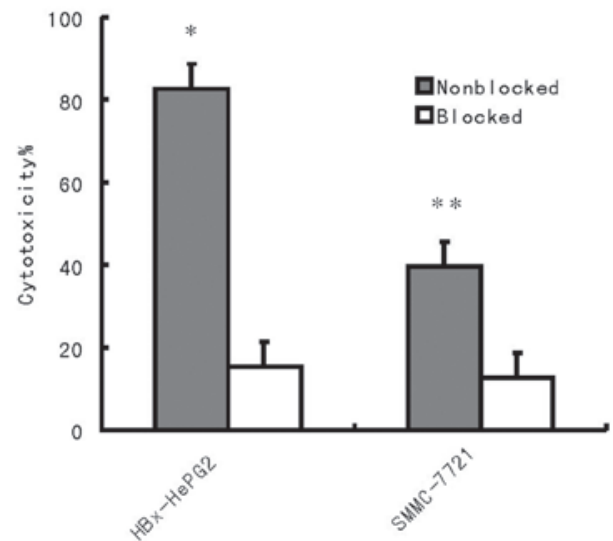

Figure 5. T cells cocultured with autologous DCs were used as effector cells and SMMC-7721 or HepG2 cells were used as the target cells. The ratio of effector:target cells was 10:1. The target cells were pre-incubated with/without an anti-MHC class I antibody, indicated as blocked and non-blocked, respectively. The results are expressed as the mean \pm standard deviation and each value represents the mean of three replicates. Statistical significance was calculated using t-test $\left({ }^{* *} \mathrm{P}<0.05\right.$, compared with the control). DC, dendritic cell; HBxAg, hepatitis B virus $\mathrm{x}$ antigen.

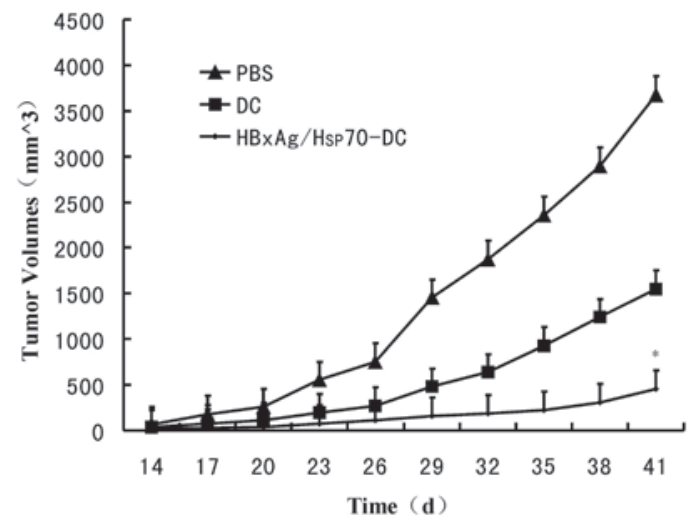

Figure 6. Xenograft and proliferation of adoptively transferred T-cells stimulated ex vivo by fusion cells, DCs and PBS control group in nude mice. umor volume was calculated as follows: $1 / 2 \mathrm{x}$ (length $\mathrm{x}$ width ${ }^{2}$ ). The data are expressed as the mean \pm standard deviation of the mice per group $(n=5)$. Statistical significance was calculated using a t-test $\left({ }^{*} \mathrm{P}<0.05\right.$, compared with the control). DC, dendritic cell; PBS, phosphate-buffered saline. Hsp70, heat shock protein 70; $\mathrm{HBxAg}$, hepatitis B virus $\mathrm{x}$ antigen.

IL-2. DCs were added at a 1:20 ratio and cocultured at $37^{\circ} \mathrm{C}$ in $5 \% \mathrm{CO}_{2}$. As shown in Fig. 3, the DCs pulsed with antigens significantly induced T-cell proliferation. The highest level of T-cell proliferation was observed when the DCs were co-pulsed with $\mathrm{HBxAg} / \mathrm{Hsp} 70$.

The cytotoxic activity against HCC cells was also assessed. Target cells were composed of HepG2 (HLA-A2 ${ }^{+} / \mathrm{HBxAg}^{+}$), SMMC-7721 (HLA-A2 ${ }^{+} / \mathrm{HBxAg}^{-}$), K562 (HLA-A2 $/ \mathrm{HBxAg}^{-}$) and LO2 cells. A small number of CTLs were induced by the HBxAg-DC vaccine; however, no significant CTL induction was observed by PBS-DCs. The results indicated that Hsp70/HBxAg-DCs specifically induced high CTL activity against $\mathrm{HBxAg-expressing}$ HepG2 cells. In the Hsp70/HBxAg-positive group, the CTL response was markedly higher compared with that observed in the Hsp70/HBxAg-negative group, indicating that the CTL response is antigen dependent (Figs. 3 and 4). 
To further confirm whether the cytotoxicity in tumors is independent of the MHC class I immunoresponse, two HCC cell lines HepG2 and SMMC-7721 were used for detection (Fig. 5). The results revealed that the cytotoxicity against HepG2 and SMMC-7721 cells was independent of MHC class I.

Establishment of Hsp70/HBxAg-DCs in the SCID mouse model. To determine the efficacy of CTLs stimulated by Hsp70/HBxAg-DCs, SCID mice were inoculated with HepG2 cells. Following inoculation for 7 days, the mice were treated with CTLs induced by fusion cells, DCs or PBS. Following treatment for 5 weeks, the fusion cell (Hsp70/HBxAg-DCs)-stimulated $\mathrm{T}$ cells significantly reduced the tumor volumes (Fig. 6). The results indicated the possible therapeutic potency of $\mathrm{T}$ cells stimulated by Hsp70/HBxAg-DCs.

\section{Discussion}

DCs are efficient antigen-presenting stimulators of B and $\mathrm{T}$ lymphocytes, which have potent immunostimulatory properties $(16,17)$. Several immunotherapies regulate DCs to stimulate the immune response (18). Previous studies demonstrated that DC-based vaccine therapy effectively stimulates T-cell immunity and kills tumor cell lines, including malignant melanoma (19), breast cancer (20) and ovarian cancer (21) cells.

A previous study suggested that HSPs, including Hsp70 and Hsp90, are potent tumor-antigen sources for pulsing DCs to activate macrophages and release specific and non-specific effecter molecules, which can increase the effect of the macrophages (22). Inducible Hsp70 may function as a crosslink between the innate and adaptive immune response $(23,24)$.

$\mathrm{HBxAg}$ is associated with several advanced liver diseases, and $\mathrm{HBxAg}$ and other etiological factors have been implicated in hepatocarcinogenesis (25). HBxAg can increase the risk of $\mathrm{HCC}$ in patients with chronic HBV infection. Previous studies have revealed that a vaccination composed of particulate hepatitis B antigen induces a specific immune response and significant antitumor effects in vivo (26) and in vitro (27).

However, whether the Hsp70/HBxAg complex enhanced the immune response in the HepG2 cells expressed by $\mathrm{HBxAg}$ remains to be elucidated. Therefore, the present study predominantly used HepG2 $\left(\mathrm{HBxAg}^{+}\right)($Fig. 1A and B) and SMMC-7721 ( $\left.\mathrm{HBx}^{-} \mathrm{Ag}^{-}\right)$cells to confirm this hypothesis. The functional maturation and proliferation of DCs is a critical step in the stimulation of tumor-specific CTLs (28). In addition, the results consistently indicated the detection of different markers, such as the CD86 costimulatory molecule, CD83 maturation marker, and other markers including CD80 and CD11c (Fig. 2A), thereby demonstrating that different antigens induce the maturation of allogeneic DCs by upregulating.

$\mathrm{CD}^{+} \mathrm{T}$ cells have an important role in the induction and maintenance of the CTL response (29). The results from the present study demonstrated that DCs pulsed with Hsp70 complexes stimulated $\mathrm{CD}^{+}{ }^{+} \mathrm{T}$ cell proliferation and unpulsed DCs exhibited few stimulatory effects. DCs pulsed with $\mathrm{Hsp} 70 / \mathrm{HBx} \mathrm{Ag}$ also activated a more marked increase in $\mathrm{CD}^{+}$ $\mathrm{T}$ cell proliferation compared with the DCs pulsed with only Hsp70 or HBxAg alone (Fig. 2B).

A previous study revealed that tumor cytotoxicity is mediated by lymphocytes, notably by CTLs (30). Therefore, in the process of tumor immunotherapy, activating tumor-specific CTLs to kill tumor cells is considered an important event (31). The present study revealed that Hsp70-DCs and HBxAg-DCs were able to induce CTL activity against HCC cells with high efficiency, consistent with this previous observation (Fig. 3). However, the data demonstrated that Hsp70- or HBxAg-DCs elicited limited CTL responses against the HCC tumor cell. Notably, after they were co-pulsed with Hsp70 and HBxAg, the Hsp70/HBxAg-DCs were able to stimulate $\mathrm{CD}^{+}{ }^{+} \mathrm{T}$ cells, which proliferated more effectively compared with those activated by DCs pulsed with HBxAg or Hsp70 alone (Fig. 3).

To further confirm that CTLs killed the HepG2 cells, and to define the specificity of the CTLs generated by the coculture of $\mathrm{T}$ cells with autologous DCs pulsed with Hsp70-peptide and/or HBxAg complexes, the cytotoxicity of the T-cell against HepG2 (HLA-A2 ${ }^{+} / \mathrm{HBxAg}^{+}$), SMMC-7721 (HLA-A2 $+/ \mathrm{HBxAg}^{-}$) cells and another human cancer cell, K562 (HLA-A2//HBxAg-), was compared. Notably, the results demonstrated that the cytotoxicity against HepG2 and SMMC-7721 cells was caused by the presence of CTLs, not by natural killer cells. The reason is that the cytotoxicity against the natural killer cell-sensitive cell line, K562, is slightly lower compared with SMMC-7721 and HepG2 cells. K562 cells are HLA-A2 $/ \mathrm{HbxAg}^{-}, \mathrm{SMMC}-7721$ cells are HLA-A2 $/ \mathrm{HBxAg}^{-}$ and $\mathrm{HepG} 2$ cells are $\mathrm{HLA}-\mathrm{A} 2^{+} / \mathrm{HbxAg}^{+}$. Thus, in conclusion cytotoxicity occurred in an antigen-specific manner (Fig. 4B).

Numerous co-stimulatory molecules, including CD80 or CD86, can induce tumor-specific T lymphocytes. The cytotoxicity induced by the antigens can be blocked by anti-MHC class I antibody (12). The present study used two HCC cell lines, HepG2 and SMMC-7721, for detection. As shown in Fig. 5, pre-incubation of the HepG2 and SMMC-7721 cells with anti-MHC class I antibody resulted in the abrogation of tumor cell lysis. Therefore, cytotoxicity against HepG2 and SMMC-7721 cells was MHC class I restricted (Fig. 4). In vivo results also confirmed that the Hsp70/HBxAg complexes significantly inhibited tumor growth in the SCID mouse model compared with the control group (Fig. 6).

In conclusion, the present study is the first, to the best of our knowledge, to demonstrate that Hsp70/HBxAg-co-pulsed with DCs elicited a marked and specific antitumor immune response. These results indicated that an $\mathrm{Hsp} 70 / \mathrm{HBx} \mathrm{Ag}$-co-pulsed DC-based cancer vaccine may be a useful application for tumor immunotherapy and may reveal promise in the development of HCC immunotherapy.

\section{Acknowledgements}

The current study was supported by grants from the Bureau of Science and Technology of Suzhou, Jiangsu Province, China (grant no. SYS201129) and the Bureau of Public Health of Jiangsu Province, China (grant no. H201413).

\section{References}

1. Arzumanyan A, Reis HM and Feitelson MA: Pathogenic mechanisms in HBV- and HCV-associated hepatocellular carcinoma. Nat Rev Cancer 13: 123-135, 2013.

2. Liu XH, Lin J, Zhang SH, Zhang SM, Feitelson MA, Gao HJ and Zhu MH: COOH-terminal deletion of $\mathrm{HBx}$ gene is a frequent event in HBV-associated hepatocellular carcinoma. World J Gastroenterol 14:1346-1352, 2008. 
3. Lehman EM and Wilson ML: Epidemiology of hepatitis viruses among hepatocellular carcinoma cases and healthy people in Egypt: A systematic review and meta-analysis. Int J Cancer 124: 690-697, 2009.

4. Wang Z, Zhang G, Wu J and Jia M: Adjuvant therapy for hepatocellular carcinoma: Current situation and prospect. Drug Discov Ther 7: 137-143, 2013.

5. Ibrahim SM, Lewandowski RJ, Sato KT: Gates VL, Kulik L, Mulcahy MF, Ryu RK, Omary RA and Salem R: Radioembolization for the treatment of unresectable hepatocellular carcinoma: A clinical review. World J Gastroenterol 14: 1664-1669, 2008.

6. Palucka K and Banchereau J: Cancer immunotherapy via dendritic cells. Nat Rev Cancer 12: 265-277, 2012.

7. Zhan HL, Gao X, Pu XY, Li W, Li ZJ, Zhou XF and Qiu JG: A randomized controlled trial of postoperative tumor lysatepulsed dendritic cells and cytokine-induced killer cells immunotherapy in patients with localized and locally advanced renal cell carcinoma. Chin Med J (Engl) 125: 3771-3777, 2012

8. Berntsen A, Trepiakas R, Wenandy L, Geertsen PF thor Straten P, Andersen MH, Pedersen AE, Claesson MH, Lorentzen T, Johansen JS and Svane IM: Therapeutic dendritic cell vaccination of patients with metastatic renal cell carcinoma: A clinical phase 1/2 trial. J Immunother 31: 771-780, 2008.

9. Murphy ME: The HSP70 family and cancer. Carcinogenesis 34 1181-1188, 2013.

10. Multhoff G, Pockley AG, Streffer C and Gaipl US: Dual role of heat shock proteins (HSPs) in anti-tumor immunity. Curr Mol Med 12: 1174-1182, 2012.

11. Ciocca DR, Cayado-Gutierrez N, Maccioni $M$ and Cuello-Carrion FD: Heat shock proteins (HSPs) based anti-cancer vaccines. Curr Mol Med 12: 1183-1197, 2012.

12. Wang XH, Qin Y, Hu MH and Xie Y: Dendritic cells pulsed with hsp70-peptide complexes derived from human hepatocellular carcinoma induce specific anti-tumor immune responses. World J Gastroenterol 11: 5614-5620, 2005.

13. Li QL, Bu N, Yu YC, Hua W and Xin XY: Ex vivo experiments of human ovarian cancer ascites-derived exosomes presented by dendritic cells derived from umbilical cord blood for immunotherapy treatment. Clin Med Oncol 2: 461-467, 2008.

14. Yang JY, Cao DY, Xue Y, Yu ZC and Liu WC: Improvement of dendritic-based vaccine efficacy against hepatitis $B$ virus-related hepatocellular carcinoma by two tumor-associated antigen gene-infected dendritic cells. Hum Immunol 71: 255-262, 2010

15. Zhang Z, Du X, Zhao C, Cao B, Zhao Y and Mao X: The antidepressant amitriptyline shows potent therapeutic activity against multiple myeloma. Anticancer Drugs 24: 792-798, 2013.

16. Steinman RM: Dendritic cells and the control of immunity: Enhancing the efficiency of antigen presentation. Mt Sinai J Med 68: 160-166, 2001.

17. Banchereau J and Steinman RM: Dendritic cells and the control of immunity. Nature 392: 245-252, 1998.
18. Ovali E, Dikmen T, Sonmez M, Yilmaz M, Unal A, Dalbasti T, Kuzeyli K, Erturk M and Omay SB: Active immunotherapy for cancer patients using tumor lysate pulsed dendritic cell vaccine: A safety study. J Exp Clin Cancer Res 26: 209-214, 2007.

19. Dannull J, Haley NR, Archer G, Nair S, Boczkowski D, Harper M, De Rosa N, Pickett N, Mosca PJ, Burchette J, et al: Melanoma immunotherapy using mature DCs expressing the constitutive proteasome. J Clin Invest 123: 3135-3145, 2013.

20. Abdul Hafid SR, Chakravarthi S, Nesaretnam K and Radhakrishnan AK: Tocotrienol-adjuvanted dendritic cells inhibit tumor growth and metastasis: A murine model of breast cancer. PLoS One 8: e74753, 2013.

21. Kandalaft LE, Powell DJ Jr, Chiang CL, Tanyi J, Kim S, Bosch M, Montone K, Mick R, Levine BL, Torigian DA, et al: Autologous lysate-pulsed dendritic cell vaccination followed by adoptive transfer of vaccine-primed ex vivo co-stimulated $\mathrm{T}$ cells in recurrent ovarian cancer. Oncoimmunology 2: e22664, 2013.

22. Gautam PK, Kumar S, Deepak P and Acharya A: Morphological effects of autologous hsp70 on peritoneal macrophages in a murine T cell lymphoma. Tumour Biol 34: 3407-3415, 2013.

23. Vrieling M, Santema W, Vordermeier M, Rutten V and Koets A: Hsp70 vaccination-induced primary immune responses in efferent lymph of the draining lymph node. Vaccine 31: 4720-4727, 2013.

24. Khanna R: Tumour surveillance: Missing peptides and MHC molecules. Immunol Cell Biol 76: 20-26, 1998.

25. Lu JW, Yang WY, Tsai SM, Lin YM, Chang PH, Chen JR, Wang HD, Wu JL, Jin SL, Yuh $\mathrm{CH}$, et al: Liver-specific expressions of $\mathrm{HBx}$ and src in the p53 mutant trigger hepatocarcinogenesis in zebrafish. PLoS One 8: e76951, 2013.

26. Buchmann P, Dembek C, Kuklick L, Jäger C, Tedjokusumo R, von Freyend MJ, Drebber U, Janowicz Z, Melber K, Protzer U, et al: A novel therapeutic hepatitis B vaccine induces cellular and humoral immune responses and breaks tolerance in hepatitis B virus (HBV) transgenic mice. Vaccine 31: 1197-1203, 2013.

27. Shi M, Qian S, Chen WW, Zhang H, Zhang B, Tang ZR, Zhang $\mathrm{Z}$ and Wang FS: Hepatitis B virus (HBV) antigen-pulsed monocyte-derived dendritic cells from HBV-associated hepatocellular carcinoma patients significantly enhance specific T cell responses in vitro. Clin Exp Immunol 147: 277-286, 2007

28. Cassel JA, Ilyin S, McDonnell ME and Reitz AB: Novel inhibitors of heat shock protein Hsp70-mediated luciferase refolding that bind to DnaJ. Bioorg Med Chem 20: 3609-3614, 2012.

29. Bajana S, Herrera-González N, Narváez J, Torres-Aguilar H, Rivas-Carvalho A, Aguilar SR and Sánchez-Torres C: Differential CD4(+) T-cell memory responses induced by two subsets of human monocyte-derived dendritic cells. Immunology 122: 381-393, 2007.

30. Harty JT, Tvinnereim AR and White DW: CD8+ T cell effector mechanisms in resistance to infection. Annu Rev Immunol 18: 275-308, 2000.

31. Hanson HL, Donermeyer DL, Ikeda H, White JM, Shankaran V, Old LJ, Shiku H, Schreiber RD and Allen PM: Eradication of established tumors by $\mathrm{CD} 8^{+} \mathrm{T}$ cell adoptive immunotherapy. Immunity 13: 265-276, 2000. 